\title{
MATERIALES PARA UNA SEMIÓTICA DE LA CULTURA ESPAÑOLA (SIGLOS XVI A XIX)
}

\author{
Francisco Abad
}

(UNED, Madrid)

La Semiótica de la cultura tiene por objeto el universo semántico que encontramos en la comunidad sociosemiótica de que tratemos, universo que se halla integrado - según concreta más Greimas - por el conjunto «de las ideologias y de las prácticas sociales significantes». Se trata pues de un todo situacional que comprende mentalidades y prácticas sociales, y ese todo es el que constituye la cultura: hablamos así de la cultura del Barroco, de la cultura de la Ilustración, etc.

Una cultura se delimita y se define temporalmente, y en ella entran ideas, actitudes, discursos, prácticas,...; se trata de una concreción en el tiempo (y en el espacio), que hay que interpretar a la luz de la historia. La consideración nada más que formalista de la cultura resulta alejada de su propia consistencia empírica, e incluso puede esconder hasta cierta pereza para el estudio: tener en cuenta a la vez los hechos históricos y los datos textuales, ideológicos, artísticos, etc., supone sin duda un esfuerzo no sólo de horas sino de acomodación mental.

Enumeramos ahora algunas entradas bibliográficas en las que se encuentran ideas y materiales para una semiótica de la cultura española en los siglos modernos. 


\section{A) Cuestiones teóricas}

BraUdel, F. (1968): La Historia y las ciencias sociales. Madrid: Alianza.

Este volumen incluye el artículo decisivo de 1958 «La larga duración», en el que se distinguen tres realidades cronológicas diferentes en el tiempo pasado: el tiempo corto del acontecimiento, la oscilación cíclica, y la historia de «larga duración»; tal larga duración consiste en una «estructura», una "coherencia» o "realidad que el tiempo tarda... en desgastar».

Braudel postula además una Historia integrada por los distintos saberes parciales y especializados, de manera que la ciencia histórica resulte «la suma de todas las Historias posibles».

Estamos ante un escrito programáticamente imprescindible.

FebVRe, L. (1970): Combates por la Historia. Barcelona: Ariel.

Nos referimos en concreto al «Examen de conciencia» que inicia como capítulo primero el volumen; en el mismo proclama con esperanza Febvre que lo que esperan de un estudioso sus colegas y en general las gentes «no es en absoluto una efusión», sino "el don de una energía»; se trata pues de tener gran rigurosidad y empuje en el trabajo.

Además desde luego hay que «concertar nuestras ideas y nuestros métodos con los de otras disciplinas"; de esta forma por ejemplo se utilizarán todos los textos y no sólo los documentos de archivo: «También un poema, un cuadro, un drama son para nosotros documentos, testimonios». Asimismo «todo hecho lingüístico pone de manifiesto un hecho de civilización».

Los estudiosos en definitiva no pueden perder de vista que el sujeto aislado constituye una abstracción, pues «la realidad es el hombre en grupor.

FonTANA, J. (1973): La Historia. Barcelona: Salvat.

Bello volumen con explicaciones muy gráficas, es decir, muy claras y persuasivas pedagógicamente. Respecto a la «Historia total» Fontana aclara que «no se trata de fabricar una síntesis universal de todos los datos que definen la evolución de una sociedad, sino de partir... de un aspecto definido de esta compleja realidad global... pero con la ambición de integrar en este estudio los datos de otros terrenos, para ayudarnos a comprender mejor al hombre y las sociedades humanas».

De lectura instructiva y agradable. 
Maravall, J. A. (1967): Teoría del saber histórico. Madrid: Revista de Occidente.

La presente tercera edición de este trabajo ofrece ampliaciones en el texto y es la última que pudo revisar su autor. Maravall lleva a cabo una brillante reflexión acerca de lo ocurrido con las ciencias en nuestro siglo, y aboga por una historiografia estructural: Las leyes de las estructuras históricas - define - son enunciados de épocas, esto es, de tiempos concretos... Leyes históricas son... «Sociedad estamental», «Monarquía Absoluta», etc..

El pasado no consiste por tanto en un mero agregado de hechos que coinciden, sino en su interrelación situacional: no van lo político por un lado, lo económico-social por otro, y el discurso artístico por otro, sino que en determinada medida que habrá que precisar según cada caso concreto, estos hechos resultan dependientes y solidarios entre sí.

El volumen de Maravall es ya un texto clásico de la historiografia española, y su planteamiento se encuentra vigente; pueden leerse con continuidad esta obra y luego la que queda mencionada de Fontana.

REGLÁ, J. (1970): Introducción a la historia. Barcelona: Teide.

Mencionamos ahora este trabajo sobre todo por sus capítulos primero y segundo: en ellos se sistematiza el marco de las distintas actividades de los hombres - las materiales y las del espíritu-, y de igual modo se distinguen las fases $A$ y $B$ de lo histórico, esto es, las expansivas y las depresivas.

Por ejemplo considerar al Renacimiento y al Barroco españoles como fases respectivamente expansiva y de recesión, ha servido para definir bien ambas culturas y para definirlas además en el tiempo: ni el Renacimiento ni lo Barroco constituyen algo que se prolongue por siglos o que reaparezca una y otra vez.

La temporalidad es una categoría que nunca debe dejar de lado el estudioso; todas las cosas tienen una fecha, y suceden unas antes que otras. Equiparar fechas, no tener en cuenta la sucesión cronológica, ignorar las huellas de la temporalidad, ..., conduce a interpretaciones desviadas o francamente erróneas.

El libro de Reglá puede servir de manual bien útil.

Stromberg, R. N. (1990): Historia intelectual europea desde 1789. Madrid: Debate.

No hemos leído y asimilado aún bien este extenso y denso libro, pero de momento llamamos ya la atención sobre lo que define como «historia intelectual» y que es en realidad «historia de las mentalidades: La esfera 
de la historia intelectual — proclama Stromberg — es la interrelación entre las ideas históricamente relevantes y el entorno social del que surgen y en el que a su vez influyen».

B) La Alta Edad Moderna

Jover, J. M. (1948): La Alta Edad Moderna. Arbor 26, 157-184.

El autor plantea cómo desde hacia 1500 hasta 1648 ocurre un período histórico de "clara unidad [y] fisonomía inconfundible» que debe ser reconocido en tanto "Alta Edad Moderna», y que se encuentra vertebrado por «la gloria y la derrota de España y de su idea». Tal Edad está caracterizada por «la lucha de la Cristiandad» contra la «Modernidad», es decir, contra el nacionalismo, la libertad religiosa, el equilibrio entre Estados,...

Por parte de los filólogos nunca hemos visto una observación que la fuerza de los hechos parece imponer: si el «Siglo de Oro» de las letras españolas va de Garcilaso a Calderón, este siglo o siglos áureos coincide históricamente con la «Alta Edad Moderna». Del Emperador Carlos a Felipe IV se extiende por tanto el Siglo de Oro español, tanto en lo político como en lo literario, la pintura, el pensamiento, etc.; si quiere fecharse así, de 1517 a 1648 .

Nos encontramos pues ante una «larga duración» de la historia que se extiende - digamos - entre 1517 y 1648 , y que debe ser analizada en tanto un todo coherente: las respectivas culturas del Renacimiento y del Barroco en España constituyen de este modo culturas globales, y la literatura no puede entenderse - fuera de lo que es inmanente-, al margen de esas culturas.

Maravall, J. A. (1984): Estudios de Historia del pensamiento español. La época del Renacimiento. Madrid: Cultura Hispánica.

Nos referimos en particular al capítulo «La fórmula del Renacimiento español», en la que el autor sintetiza y propone: «La expansión económica y social en Castilla anterior aproximadamente a $1560 \ldots$ inspiró una particular manifestación en el Renacimiento español... Se trata de una decidida inclinación hacia los "modernos",... [a la] "emulación" frente a los ["antiguos"]».

SÁNCHEZ MONTES, J. (1951): Franceses, protestantes, turcos. Los españoles ante la politica internacional de Carlos $V$. Madrid: CSIC. 
Este trabajo no deja de tener atisbos de lo que será la Historia de la mentalidades, y en este sentido su lectura no deja de resultar sugerente. No constituye una pieza fundamental en la muy rica bibliografía carolina, pero tiene interés.

C) Sobre el Barroco

Argan, G. C., (1964): La Europa de las capitales. Barcelona: Skira.

Traducción castellana de la obra importante de un autor de relieve; en ella se recogen o se proponen tesis fundamentales que la mejor crítica siempre ha tenido en cuenta.

Escribe así Argan: «Persuadir es ahora mucho más importante que demostrar [...] La defensa y revalorización de las imágenes... es la gran empresa del Barroco [...] Lo que importa es que la comunicación humana sea... solicitada... por el deseo de formar grupos de hombres solidarios en las mismas creencias y opiniones [...] En el XVII... la Iglesia, empeñada en una acción más bien de propaganda que de lucha,... quiere demostrar que a todos los fieles hasta los más humildes está abierta la vía de la gloria celestial».

Volumen de lectura conveniente, aunque creemos ha pasado bastante desapercibido.

Jover, J. M. (1949): Sobre la conciencia histórica del Barroco español. Arbor 39, 355-374.

Análisis historiográfico e histórico del «tránsito de los antiguos tiempos - la Historia como sucesión de Monarquías-, a los nuevos - la Historia como serie de luchas en busca del equilibrio».

MARAVAll, J. A. (1944): La teoría española del Estado en el siglo XVII. Madrid: IEP.

Exposición rica en contenido, y que en general importa porque ya se postula en ella la concepción del siglo XVII en tanto "un concepto histórico» o de «época»: se trata justamente de «la época del Barroco» que se había iniciado «en los últimos años de la centuria anterior».

Denso y profundo estudio (V. Palacio Atard).

- (1948): Barroco y racionalismo. Finisterre 34, 171-175.

El XVII es el momento del Barroco pero «no menos la época del racionalismo», nos advierte el autor; este racionalismo puede estar al servicio - por ejemplo - de «una dirección regulada del discurso». 
Sin duda el Seiscientos es asimismo el siglo del racionalismo y de la revolución científica, y no podrá ser definido sin tener en cuenta el alcance intelectual y social de tales hechos.

- (1949): Reseña de E. Moreno Báez, Lección y sentido del Guzmán de Alfarache. Escorial XIX, 435-439.

Escribe el autor: «El estudio de las formas, sin que por esto le neguemos su magnífica condición..., o el de los antecedentes y filiaciones de una obra, etc., no pueden por sí darnos la inmediata aprehensión de una obra literaria si no alcanzamos el fondo de su sentido en el ámbito cultural en que surge y al que pertenece».

Estamos de acuerdo con el espíritu de esta proclama: en el estudio de la obra de arte verbal se hace necesario - creemos nosotros- tanto el análisis de sus formas (pues lo inmanente sólo se explica por lo inmanente), como el análisis histórico que descubre el sentido de los textos. No es más importante lo uno o lo otro; las formas o el sentido poseen igual relieve.

Orozco DíAZ, E. (1947): Temas del Barroco de poesia y pintura. Granada: Universidad.

No deja de ser un error el olvidar demasiado - como a veces se hace hoy- esta obra: estamos ante uno de los mejores libros de autor español en torno al Barroco. Sus tesis no lo dicen todo, pero siguen vigentes; sus análisis y ejemplos se mantienen por igual vivos.

-Introducción al Barroco, I. Granada: Universidad.

Mencionamos ahora este volumen por el artículo que se recoge en él «Sobre el Barroco y la periodización en la Historia del arte y de la literatura». El autor disiente de que se considere al Renacimiento «como un gran período que abarcaría desde fines del siglo XIV hasta el siglo XVIII», y postula se reconozca la necesidad de admitir - por adecuación a los hechos - «una periodización que fragmenta el macroperíodo renacentista con el que se había querido abarcar toda la Edad moderna».

En su planteamiento Orozco coincide con los historiadores más rigurosos, a quienes la realidad empírica impide analogar unos tiempos con otros; por ejemplo Pierre Vilar - y a propósito del Quijote - ha insistido en ello. 
D) La Ilustración

CAso González, J. (1988): De Ilustración y de ilustrados. Oviedo: Universidad.

La «Introducción» de este volumen misceláneo (pp. 11-19) la plantea el autor como «síntesis de lo que yo pienso ahora»; estamos pues ante un balance hecho en la madurez sobre la cultura ilustrada. Caso propone por ejemplo: a) «Educar era hacer hombres libres,... poner a cada uno en condiciones adecuadas para disponer de sí mismo en todos los aspectos»; b) «La Ilustración no fue una filosofia ni siquiera un sistema ideológico, sino unos cuantos, y no muchos, principios generales».

No creemos por nuestra parte que quepa mantener ambas cosas: a) la educación en efecto se hallaba diversificada estamentalmente para que así cada uno permaneciese en la pertenencia social que ya tenía; b) la Ilustración es una época histórica definible como un todo y una situación concreta, ya que no se trata sólo de la vigencia de unos pocos principios generales. La envergadura histórica de la primera Ilustración y de la Ilustración propiamente dicha en España, deriva de consistir en un sistema o totalidad en la que coinciden y se interrelacionan determinados factores y determinadas características de lo histórico.

Sobre «los límites estamentales de la educación en el pensamiento ilustrado» cfr. ahora Maravall, J. A. (1991): Estudios de Historia del pensamiento español. Siglo XVIII. Madrid: Mondadori (pp. 460-475).

Domínguez ORTIZ, A. (1987): Estudios de Historia económica y social de España. Granada: Universidad.

Entre las bastantes publicaciones de Domínguez Ortiz que podrían (y deberían) citarse, nos referimos en particular al capítulo de este libro «La reconstrucción del Estado español por los primeros Borbones»; en él se reivindica la «sustantividad propia» del espacio cronológico que va de 1700 a 1808 - diluida a veces por otros estudiosos-, y se subraya la trascendencia histórica del «nuevo Estado» español «con contornos bien definidos» $\mathrm{y}$ «administración unificada» que entonces se constituye.

Páginas de un gran madurez y solidez.

JoVER, J. M. y HeRnÁNDEZ SANDOICA, E. (1985): «España y los tratados de Utrecht». En Historia de España Menéndez Pidal XXIX/1, 337-440. Madrid: Espasa-Calpe.

Estudio y glosa agudos del «ambiente colectivo de historia recomenzada» en que hubieron de vivir los españoles de 1713. 
En el marco de tal estado de ánimo cabe entender acaso - por ejemplo- - la fundación de la Real Academia Española de la Lengua.

\section{Palacio Atard, V. (1947): El Despotismo Ilustrado español. Arbor 22, 27-52.}

Inventario de los rasgos históricos que caracterizan al «Despotismo Ilustrado» español peculiar de nuestro siglo XVIII.

SÁNCHEZ AGESTA, L. (1953): El pensamiento politico del despotismo ilustrado. Madrid: IEP.

Planteamiento pionero de los problemas intelectuales de la centuria en España, en el que se apuntan cuestiones sobre las que luego han ahondado los estudiosos: la utilidad, el interés individual, el empeño pedagógico,...

Sigue siendo un trabajo de necesaria lectura.

E) El Ochocientos

JOVER, J. M. (1990 18 ): «La época del Naturalismo»; «La plenitud de la

Edad de Plata». En Introducción a la Historia de España, 740-758 y 877-899. Barcelona: Teide.

Mencionamos estos dos capítulos de manual porque en ellos se sugiere muy bien el marco histórico e intelectual real en el que se despliega el extraordinario auge cultural de la España de hacia fines del siglo pasado y del primer tercio del presente; el renacimiento de las culturas regionales o la crisis espiritual de los años treinta quedan así recogidos.

Estamos ante una muestra de la complejidad real con que hay que abordar los hechos por ejemplo literarios: el pasado posee siempre una riqueza de factores situacionales que el análisis nunca debe ignorar.

- (1991): Realidad y mito de la Primera República. Madrid: Espasa-Calpe.

Cala honda en los componentes históricos reales y en la memoria histórica del 73; se analizan textos de Emilia Pardo Bazán y sobre todo de Galdós, y el autor se detiene asimismo en una figura de gran atractivo en el Ochocientos español y que parece haber pasado casi desapercibida para los filólogos: Manuel de la Revilla. 
- (1992): La civilización española a mediados del s. XIX. Madrid: Espasa-Calpe.

A una segunda parte teórica y metodológica fundamental denominada «Por una Historia de la civilización española» antecede el estudio analítico particular de la «Política y civilización en España» entre 1834 y 1874. El capítulo primero posee gran densidad en sus alusiones, de tal manera que se hace necesario leerlo más de una vez; el segundo constituye un planteamiento que hasta ahora no se había hecho en nuestra historiografia.

VICENS VIVES, J. (1981): «La cultura burguesa». En Historia general moderna II, 439-503. Barcelona: Vicens-Vives.

Se trata del cap. XIII del conocido manual general de Historia Moderna que hizo Vicens, capítulo sugerente y que encierra muy bien los problemas intelectuales y espirituales del Ochocientos. cindible.

No hay que subrayar que la lectura de Vicens resulta siempre impres-

F) Conclusiones

El estudio de la anterior bibliografia y sobre todo el de los hechos reales y los textos literarios induce algunas conclusiones o tesis:

1. El «Siglo de Oro» español consiste en un despliegue extraordinario de la cultura que se produce justamente en la «Alta Edad Moderna) (hacia 1500 ó 1517-1648); los problemas de las letras del Siglo de Oro son los problemas planteados en esa Alta Edad Moderna.

2. El Barroco aparece vinculado a la Contrarreforma, aunque ahora a veces tiende a subrayarse menos. Es lógico que en nuestros tiempos se enfatice sobre los factores sociales de la cultura barroca, pero hay que no perder de vista la propia situación del Quinientos y del Seiscientos y entenderla conforme ella misma fue.

3. El Barroco supuso asimismo la cultura de la revolución científica; entre los componentes del XVII se cuenta esta eclosión del pensamiento sobre el mundo natural.

4. Debemos entender por «Ilustración» una realidad histórica de época, un todo particular o sistema concreto acaecido en el pasado; no se trató sólo de «unos cuantos principios generales», según se postula. 
5. Todavía menos creemos nosotros que cabe decir que la educación ilustrada se proponía «hacer hombres libres» que pudiesen disponer de sí mismos; los hombres del Antiguo Régimen no eran libres sino que se hallaban vinculados a su pertenencia estamental, y la educación trataba de asegurar tal pertenencia.

6. El concepto contemporáneo de España se origina en el XVIII, con el nuevo Estado que surge tras Utrech y la ordenación de la Península según una Nueva Planta.

7. Hay un centro de gravedad en la historia y la cultura española aún poco estudiado y - sobre todo-, poco sistematizado: nos referimos a la «larga duración» que va de 1833 a 1939. Junto al nacionalismo que atiende al Siglo de Oro - Américo Castro, etc.cabe un análisis que mira más hacia el futuro y que es el que se ocupa de los tiempos posteriores a 1700 . 